\title{
DỨcin
}

Technological University Dublin ARROW@TU Dublin

2003-01-01

\section{Determinants of Sexual Behaviour}

\author{
Kevin Lalor \\ Technological University Dublin, kevin.lalor@tudublin.ie \\ Cathal O'Regan \\ Siobhan Quinlan
}

Follow this and additional works at: https://arrow.tudublin.ie/aaschsslarts

Part of the Psychology Commons, and the Sociology Commons

\section{Recommended Citation}

Lalor, K., O'Regan, C. \& Quinlan, S. Determinants of sexual behaviour. Irish Journal of Sociology, 2003, Vol.12 (2), pp. 121-133. doi:10.1177/079160350301200208

This Article is brought to you for free and open access by the Social Sciences at ARROW@TU Dublin. It has been accepted for inclusion in Articles by an authorized administrator of ARROW@TU Dublin. For more information, please contact arrow.admin@tudublin.ie, aisling.coyne@tudublin.ie,gerard.connolly@tudublin.ie.

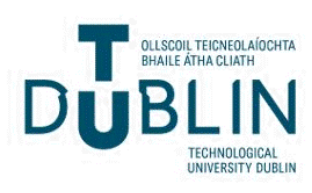




\section{DETERMINANTS OF SEXUAL BEHAVIOUR AMONGST A SAMPLE OF COLLEGE STUDENTS}

\section{INTRODUCTION}

A common theme of the media portrayal of adolescent sexual behaviour in Ireland is that of the 'debauched and decadent lifestyles' referred to by Devlin (this volume). Devlin details a number of instances in both tabloid and broadsheet newspapers of coverage of adolescent sexual behaviour, characterised by moral panic yet (largely) devoid of empirical or statistical content.

Inglis (1998) suggests four main discourses on sexuality in Ireland: traditional, progressive, liberal and radical. To illustrate, he explores the discourses surrounding the development of the 'Relationships and Sexuality Education' programme by the National Council for Curriculum and Assessment. These discourses range from outright opposition from a variety of Catholic interest groups, to mixed responses from teachers, to a generally positive response from media commentators. Of course, most debate on adolescent sexual behaviour is informed by beliefs in how young people should, or should not, behave. Young peoples' actual behaviour can be sidelined in such value-laden debates (and pronouncements).

The purpose of this paper is to contribute to the debate by detailing the sexual behaviour of a sample of college students, predominantly in their late teens (or, at least, the behaviour they say they engage in - see comments below on methodological reliability). A sample of 247 students of the Dublin Institute of Technology were surveyed regarding their experiences of both consensual and unwanted sexual experiences during childhood and adolescence. The findings regarding their unwanted sexual experiences whilst younger than 16 years of age have been reported elsewhere (Lalor, 1999). This paper examines the consensual sexual experiences of the sample before their sixteenth birthdays and a number of related issues, such as sexual orientation and duration of boyfriend/girlfriend relationships. It also explores the determinants of sexual behaviour amongst the sample. 
MacHale and Newell (1997) surveyed the sexual behaviour and sex education of 2754 pupils aged between 15 and 18 years, attending 40 second level schools in Galway City and County, by an anonymous self-administering questionnaire. Twenty one per cent of the pupils had had sexual intercourse, with boys more than twice as likely as girls to have had sexual intercourse. The mean age of first coitus was 15.5 years. Over half of the respondents stated that the first time they had sex was with a 'casual' partner or 'one night stand', with 35\% claiming that alcohol and $9 \%$ claiming that non-prescribed drugs were a contributory factor. Male participants were more than twice as likely than female participants to have first sexual intercourse with a casual partner. Regarding the frequency of sexual intercourse experiences, just under half the participants $(242 ; 48 \%)$ reported having intercourse only occasionally with one fifth of participants $(104 ; 20 \%)$ having intercourse weekly or more frequently.

In addition, the majority of both male and female participants $(235 ; 72 \%$ and 156 ; $72 \%$ respectively) stated they used a condom at first sexual intercourse but, of the 475 pupils who had sex regularly, only $67 \%$ used condoms 'all the time' with $33 \%$ 'sometimes' or 'never' using condoms.

Also, a study was conducted by the Midland Health Board (1996) which explored the sexual practices of 1,645 male and female (892 and 762 respectively) 16-18 year old secondary school students from 12 randomly selected schools within the Midland Health Board catchment area. The study reported that $32 \%$ of the 1,645 participants stated they had sexual intercourse and there was no significant difference between socio-economic groups. The study also highlighted that males were significantly more likely to have had sexual intercourse than females, with $38 \%$ of males and $26 \%$ of females stating they had had sexual intercourse. The study reveled that $75 \%$ of the 447 participants who stated they had sexual intercourse were between 15 and 17 years of age when they first had sexual intercourse. In addition, $26 \%$ of those who had sexual intercourse stated they had three or more sexual partners. Regarding contraceptive use, $82 \%$ of the sexually active participants stated that they used contraception, with $70 \%$ of the participants using contraception the first time they had sexual intercourse. 
A study conducted by Alliance (1997) explored the attitudes and values of young people in Cork City towards sexuality, relationships, AIDS, alcohol and drug use. The study consisted of a self-administered questionnaire of 800 young people between the ages of 15 and 24. Four focus groups were also conducted. The results of the study showed that $30 \%$ of the female participants and $45 \%$ of male participants in the 15-17 years old category had had sexual intercourse. In addition, $22 \%$ of all female participants and $32 \%$ of all male participants had their first sexual intercourse experience by the age of 16 . The study also showed that $81 \%(n=64)$ of the $15-17$ year old sexually active females have had two sexual partners or less, and $46 \%(n=24)$ of the 15-17 year old sexually active males reported having three sexual partners or more.

Fitzpatrick, Fitzpatrick and Turner (1997) examined the sexual behaviour and sociodemographic characteristics of 120 teenage mothers attending a public adolescent antenatal clinic. The ages of the teenagers attending the clinic ranged from 14 to 19 , with a mean age of 17.7 years. Only five participants were under 16 years of age. There was little indication of promiscuity within the sample. For example, ninetyseven $(80.8 \%)$ participants stated that they had sexual intercourse with one partner, 21 $(17.5 \%)$ stated that they had two sexual partners and two (1.7\%) said that they had three sexual partners, with $105(87.5 \%)$ stating that they were still in a relationship with the father of the child. Of the 120 participants, only $62(51.7 \%)$ had used contraception in the past, with only 33 (27.5\%) using contraception 'regularly' and only five participants stated that they 'always' used contraception. Five participants (4.2\%) had had a previous pregnancy; of these one had an abortion, one had a miscarriage and the remaining three gave birth.

Thus, these adolescent pregnancies would appear to be the result of low levels of contraceptive use, rather than rampant promiscuity or a 'melt-down' in the 'morals' of young people. It is interesting to note that the number of births to adolescents in Ireland has not significantly changed in the last 20 years. However, the number of births to single adolescent mothers has increased. In 1972, $24 \%$ of births to women under 20 were outside marriage, however, by 1992, 89.3\% of births to women under 20 were outside marriage. In 1997, 2,894 women under 20 years of age gave birth in 
Ireland, representing $5.5 \%$ of all births, with the majority (95\%) of these births to single women.

A survey of the sexual behaviour of a sample of 405 students of the Dublin Institute of Technology was undertaken recently by the Students' Union (DITSU, 2000). Data was collected by means of personal interview. Results suggest that $79 \%$ of respondents have had "full sexual intercourse," although only $15 \%$ of the total sample report having "regular sexual intercourse." Unfortunately, no data is available as to the age respondents were when they first experienced intercourse, nor do we know which proportion of students from Years one, two, three and four responded positively to this question. That is, we do not know what proportion of First Years (most of whom are 18 years old) answered this question in the affirmative, relative to Fourth Years (most of who we can presume to be 22 years of age). A subsequent question asks respondents when they "became sexually active." Forty one per cent reported becoming "sexually active" before their Leaving Certificate and a further $37 \%$ said it was during their Leaving Certificate (which most students sit at 17 or 18 years of age). However, as "becoming sexually active" is not operationalised, this item tells us less than it might first appear to do. Students were also asked to describe their sexual orientation; $97 \%$ reported being heterosexual, $2 \%$ reported being bi-sexual and $1 \%$ reported being homosexual.

\section{The law and sexual behaviour amongst adolescents}

A number of Acts regulate the sexual behaviour of young people. Sections 1 and 2 of the Criminal Law (Amendment) Act, 1935 ban 'unlawful carnal intercourse' with girls under 15 (maximum penalty: life imprisonment) and girls aged 15 or 16 (maximum penalty: five years imprisonment). The offence is committed by the male party; his age (nor her consent) is no defence (Ryan, 1997). 'Statutory rape' is not a strictly legal concept.

The law appears to permit consensual non-penetrative sexual activity between a male and a female (or between 2 females) where the female is fifteen or older. This is a result of Section 14 of the Criminal Law (Amendment) Act, 1935: 
"Defence of consent by person under 15 years of age

14 - It shall not be a defence to a charge of indecent assault upon a person under the age of fifteen years to prove that such person consented to the act alleged to constitute such indecent assault."

By implication, such a defence is open to parties aged 15 or over, provided that the activity does not involve sexual intercourse.

This is not the case for homosexual acts. Section 4 of the Criminal Law (Sexual Offences) Act, 1993 decriminalised anal intercourse subject to new requirements penalising such behaviour with persons under age 17. The Act makes it an offence to engage in 'gross indecency' where both parties are male and one is under the age of 17 , even where both of the parties consent.

To summarise:

\begin{tabular}{|l|c|l|}
\hline \multicolumn{1}{|c|}{ Activity } & Age of consent & \multicolumn{1}{c|}{ Offence } \\
\hline Sexual intercourse & 17 & Unlawful carnal intercourse \\
\hline $\begin{array}{l}\text { Acts other than sexual intercourse } \\
\text { (heterosexual and lesbian) }\end{array}$ & 15 & Indecent assault \\
\hline Any homosexual acts & 17 & Gross indecency \\
\hline
\end{tabular}

Table 1: summary of law governing sexual behaviour in adolescence

Describing the origins of the Criminal Law (Sexual Offences) Act, 1993, Ryan (1997) ponders:

"Doubtless public opinion would ... have recoiled at the prospect of 15-yearold males engaging in sexual activity, of however timid a nature, with other males. But what, one may ask, makes a 15-year-old Irish girl so much more robust in the face of male advances that she requires less protection than her 
male contemporaries?” (pp. 41-42).

\section{METHODOLOGY}

For the present study, an anonymous questionnaire was administered to 247 students of the Dublin Institute of Technology during the academic year 1996-1997. A range of demographic questions were presented as well as a range of questions relating to sexual experiences whilst under age 16. Other questions examined sexual orientation and respondents' length of sexual relationships. Prior to the distribution of the questionnaire, approximately fifteen minutes was spent with the students discussing the research, covering the pertinent ethical issues and allowing for any questions to be answered.

It is important to note that, as with all such 'self-report' surveys of sexual behaviour, the results have to be interpreted cautiously. Sexuality and sexual behaviour are notoriously difficult to survey in a quantitative way. Responses may be influenced by bravado, modesty, shame, denial and a range of cultural discourses which determine how respondents believe they should report their sexual behaviour, regardless of the degree of questionnaire anonymity. Such confounding variables may or may not be conscious. For example, Rajani \& Kudrati (1996) describe the widespread initiation ritual of anal sex, regarded as "an important rite of passage in identity formation" (1996: 308) amongst street boys in Mwanza, Tanzania. Also frequent amongst street boys was anal intercourse initiated by one boy on another (typically) more docile boy for the relief of sexual tension and mutual 'comfort sex.' Paradoxically, to be perceived as mhanisi (or 'faggot') is reportedly the worst form of humiliation amongst street boys. Thus, categories of sexual behaviour (or, as in the above instance, sexual orientation) may not be as clear-cut as initially imagined.

\section{RESULTS}

\section{Introduction}


Demographic characteristics of the sample are presented, followed by data describing the adolescent sexual experiences of the sample and other related issues. A focus throughout shall be the extent to which variables such as age, gender and geographic origins of respondents determines their level of sexual experience.

Age, gender and geographic origin

A total of 247 students of the Dublin Institute of Technology were surveyed. Approximately $75 \%$ were in the 18-20 age group, with smaller numbers of older age groups. Seventy one per cent were female, which is typical of the student profile in the courses that were surveyed.

\begin{tabular}{|lc|c|c|c|}
\hline & $\begin{array}{c}\text { Male } \\
\%(N o .)\end{array}$ & $\begin{array}{c}\text { Female } \\
\%(\text { No.) }\end{array}$ & $\begin{array}{c}\text { Total } \\
\%(\text { No.) }\end{array}$ \\
\hline Age & $18-20$ & $22.67(56)$ & $52.22(129)$ & $74.89(185)$ \\
\hline & $21-25$ & $4(10)$ & $14.57(36)$ & $18.62(46)$ \\
\hline & $26-30$ & $1.2(3)$ & $3.64(9)$ & $4.85(12)$ \\
\hline & $31-35$ & $0.4(1)$ & $0.8(2)$ & $1.21(3)$ \\
\hline & $36-40$ & $0.4(1)$ & $0(0)$ & $0.4(1)$ \\
\hline Total & $28.74(71)$ & $71.25(176)$ & $100(247)$ \\
\hline
\end{tabular}

Table 2: Sample by age and gender.

Approximately half of the sample originate (defined as, 'where have you lived for the longest period until age 16?') in Dublin City or County; the remainder come from a range of medium and small towns and rural areas. Very few (9) come from Cork, Waterford, Limerick or Galway cities: 


\begin{tabular}{|l|l|l|}
\hline & No. & $\%$ of total \\
\hline Dublin City or County & 114 & 46.5 \\
\hline Cork, Waterford, Limerick or Galway city & 9 & 3.7 \\
\hline Town with population between 10,000-50,000 & 27 & 11 \\
\hline Town with population between 5,000-10,000 & 14 & 5.7 \\
\hline Town/village with population less than 5,000 & 37 & 15.1 \\
\hline Rural/Farm & 37 & 15.1 \\
\hline Other & 9 & 3.6 \\
\hline Total & 247 & 100 \\
\hline
\end{tabular}

Table 3: Origin of respondents

Consensual sexual experiences whilst under age 16

\begin{tabular}{|l|c|c|c|c|c|c|}
\hline & \multicolumn{3}{|c|}{ Partner 21 yrs. + } & \multicolumn{3}{c|}{ Partner <21 yrs. } \\
\hline & Male & Female & Total & Male & Female & Total \\
& & & & & \\
& \% within & \% within & \% within & \% within & \% within & \% within \\
& gender & gender & gender & gender & gender & total \\
& $($ No.) & $($ No.) & $($ No.) & $($ No.) & $($ No.) & $($ No.) \\
\hline Kissing & 20.3 & 20.1 & 20.2 & 91.5 & 81.4 & $84.4 \%$ \\
& $(13)$ & $(33)$ & $\left(46^{*}\right)$ & $(65)$ & $(140)$ & $\left(205^{*}\right)$ \\
\hline Genital & 0 & 1.8 & 1.3 & 49.3 & 31 & $36.3 \%$ \\
fondling & $(0)$ & $(3)$ & $(3)$ & $(34)$ & $(53)$ & $(87)$ \\
\hline Masturbation & 0 & 2.4 & 1.7 & 40 & 26.3 & 30.3 \\
& $(0)$ & $(4)$ & $(4)$ & $(28)$ & $(45)$ & $(73)$ \\
\hline Oral sex & 1.4 & 1.2 & 1.3 & 24.3 & 13.2 & 16.5 \\
& $(1)$ & $(2)$ & $(3)$ & $(17)$ & $(22)$ & $(39)$ \\
\hline Intercourse & 0 & 1.2 & 0.8 & 18.6 & 9.9 & 12.4 \\
& $(0)$ & $(2)$ & $(2)$ & $(13)$ & $(17)$ & $(30)$ \\
\hline
\end{tabular}

Table 4: Consensual sexual experiences below age 16 (*totals exceed sample size due to doubling counting)

The data is presented according to the age of respondents' sexual partners. A five year age gap is of interest when studying the exploitative/abusive sexual experiences 
of adolescents (Lalor, 1999). For the purposes of this paper, the primary focus is on the sexual experiences respondents have had whilst under age 16 with others aged less than 21 years. Such partners shall be termed 'age mates.'

A number of interesting patterns are evident in Table 4. Firstly, adolescents below age 16 are considerably more likely to have sexual experiences with people under age 21 , compared to people aged 21 years or more. Thus, for example, whilst $1.3 \%$ of the sample have experienced 'genital fondling' with somebody over age 21 (whilst they were under age 16), 36.3\% have done so with somebody closer to their own age (that is, under age 21). Similarly, whilst $0.8 \%$ of the sample have had intercourse with somebody over age 21 (whilst under 16 years), 12.4\% have had intercourse with somebody closer in age (that is, under 21). Indeed, aside from kissing, very few respondents had any sexual relations with people aged over 21 .

As a general comment, we can say that the majority of 16 year olds (84\%) have kissed an 'age mate' (that is, a partner younger than 21); about one third (30\%) have 'been masturbated by, or masturbated' an age-mate, and just over $12 \%$ have had intercourse. For the $10.22 \%(n=18 ; 17$ with age mates and one other respondent with a $21+$ year old only) of females in the sample who have had intercourse, their male partners (regardless of age) have committed the offence of unlawful carnal intercourse.

Another interesting trend is the gender differences in sexual experiences whilst younger than age 16. Males are twice as likely to have oral sex or intercourse and about one and a half times as likely to have experienced masturbation by another person and genital fondling with 'age-mates' than females.

The opposite is the case for sexual experiences with people aged over 21. Here, females are more likely to have had such experiences. For example, two females have had intercourse with somebody over age 21 , whilst younger than 16 , compared to no males.

After age 16, such gender differences do not persist, at least with regard to sexual intercourse. Respondents were asked if they had ever had intercourse and no gender 
difference exists: some $61 \%$ of males and $58 \%$ of females have had sexual intercourse. However, if we consider 18-20 year olds only and exclude older respondents, a gender difference remains: 57\% of 18-20 year old males have had sexual intercourse, compared with $47.7 \%$ of females.

\section{Urban-rural differences}

Where an adolescent grows up has an influence on his/her degree of sexual behaviour. Significant differences are reported by those who report growing up in towns (pop. $5,000+)$, large towns $(10,000+)$ or cities (Cork, Waterford, Limerick, Galway or Dublin) (collectively deemed 'urban') and those who reported growing up in villages (pop. $<5,000$ ), rural areas or farms (collectively deemed 'rural'). Table 5 below illustrates the degree of sexual activity experienced before 16 years of age with a partner younger than 21 years of age:

\begin{tabular}{|l|l|l|l|}
\hline & $\begin{array}{l}\text { Urban } \\
\%\end{array}$ & $\begin{array}{l}\text { Rural } \\
\%\end{array}$ & Significance \\
\hline Genital fondling & 43.75 & 21.25 & $\mathrm{p}=.0028$ \\
\hline Masturbation & 38.13 & 14.81 & $\mathrm{p}=.00066$ \\
\hline Oral sex & 21.38 & 6.41 & $\mathrm{p}=.011$ \\
\hline Intercourse & 16.25 & 4.94 & $\mathrm{p}=.042$ \\
\hline
\end{tabular}

Table 5: Urban-rural differences in sexual experiences before age 16

As we can see, people younger than 16 from 'urban' areas are significantly more likely to engage in all forms of sexual behaviour than young people from 'rural' areas.

It is interesting to look at the gender differences in sexual behaviour before age 16 amongst rural dwellers: 


\begin{tabular}{|l|l|l|l|l|}
\hline & $\begin{array}{l}\text { Rural male } \\
\%\end{array}$ & $\begin{array}{l}\text { Rural female } \\
\%\end{array}$ & Significance & N \\
\hline Genital fondling & 53.85 & 14.93 & .0039 & 80 \\
\hline Intercourse & 21.43 & 1.49 & .0086 & 81 \\
\hline
\end{tabular}

Table 6: Male-female differences in sexual behaviour below age 16 amongst rural dwellers

That is, rural males are significantly more likely than rural females to have sexual experiences before age 16 .

Place of origin continues to have an influence on later sexual behaviour. Respondents were asked whether they had ever been in a sexually active relationship (not necessarily including sexual intercourse) and whether they had ever had intercourse. These responses are categorized by place of origin below. Sample sizes in some of the 'place of origin' categories are too small to be useful (for example, only 9 of the sample come from cities outside Dublin, that is, Cork, Waterford, Limerick and Galway). However, the larger sub-samples are presented below:

\begin{tabular}{|l|c|c|c|}
\hline & $\begin{array}{c}\text { Ever been in a sexually active } \\
\text { relationship (not necessarily } \\
\text { involving intercourse)? } \\
\% \text { (No.) }\end{array}$ & $\begin{array}{c}\text { Ever had sexual } \\
\text { intercourse? }\end{array}$ & Total \\
\hline Dublin city or county & 76.3 & 64 & $\%$ (No.) \\
\hline Town, pop. 10000 - 50000 & $(87)$ & $(73)$ & 100 \\
& 88.9 & 59.3 & 100 \\
\hline Town/village pop. $<5000$ & $(24)$ & $(16)$ & $(27)$ \\
\hline Rural/farm & 78.4 & 58.3 & 100 \\
& $(29)$ & $(21)$ & $(37)$ \\
\hline
\end{tabular}

Table 7: Urban-rural differences in 'ever been in a sexual relationship' and 'ever had sexual intercourse' 
As we can see, there are few differences between Dublin and small towns/villages of less than 5000. However, there are considerable differences between both these two categories and those respondents from farms or rural areas. Whilst $64 \%$ of those from Dublin have had intercourse, only $39 \%$ of those from rural and farm areas have.

\section{Age-related differences}

The age cohorts of the sample were strong determinants of respondents' sexual experiences. As we might expect, the data shows a significant difference between 1820 year olds and those aged 21 or more in whether or not they had ever been in a sexually active relationship.

\begin{tabular}{|l|c|c|}
\hline & $\begin{array}{c}\text { Have been in a sexually active } \\
\text { relationship } \\
\%(\text { No. })\end{array}$ & $\begin{array}{c}\text { Have not been in a sexually } \\
\text { active relationship } \\
\%(\text { No. })\end{array}$ \\
\hline $18-20(\mathrm{n}=185)$ & $70.27(130)$ & $29.7(55)$ \\
\hline $21-25(\mathrm{n}=45)$ & $84.4(38)$ & $15.6(7)$ \\
\hline $26-30(\mathrm{n}=12)$ & $91.7(11)$ & $8.3(1)$ \\
\hline $31-35(\mathrm{n}=3)$ & $100(3)$ & $0(0)$ \\
\hline
\end{tabular}

Table 8: Age-related differences in involvement in sexually active relationships $(n=245 ;$ missing $=2)$

Thus, whilst $84.4 \%$ of $21-25$ year olds have been in a sexually active relationship, just $70.3 \%$ of $18-20$ year olds have.

Not surprisingly, these age differences extend to whether or not respondents report having had sexual intercourse: 


\begin{tabular}{|l|c|c|c|}
\hline Age & $\begin{array}{c}\text { Have had intercourse } \\
\%(\text { No.) }\end{array}$ & $\begin{array}{c}\text { Have not had } \\
\text { intercourse } \\
\%(\text { No. })\end{array}$ & $\begin{array}{c}\text { Total } \\
\%(\text { No.) }\end{array}$ \\
\hline $18-20$ & $50.54(93)$ & $49.46(91)$ & $76(184)$ \\
\hline $21-25$ & $81.82(36)$ & $18.18(8)$ & $18(44)$ \\
\hline $26-30$ & $100(11)$ & $0(0)$ & $4.5(11)$ \\
\hline $31-35$ & $100(3)$ & $0(0)$ & $1.2(3)$ \\
\hline Total & $59.09(143)$ & $40.91(99)$ & $100(242)$ \\
\hline
\end{tabular}

Table 9: Age by experience of sexual intercourse

Thus, amongst 18-20 year olds, 50.54\% have had sexual intercourse. Amongst 21-25 year olds $(n=44), 81.8 \%$ have had intercourse and amongst $26+$ year olds $(n=14)$, $100 \%$ have had sexual intercourse.

\section{Boyfriend/girlfriend relationships}

Respondents were asked to indicate what was the longest relationship they have had with a boyfriend or girlfriend.

\begin{tabular}{|l|l|l|l|l|l|l|}
\hline Age & $\begin{array}{l}<3 \text { months } \\
\%\end{array}$ & $\begin{array}{l}3-11 \text { months } \\
\%\end{array}$ & $\begin{array}{l}12-17 \\
\text { months } \\
\%\end{array}$ & $\begin{array}{l}>18 \text { months } \\
\%\end{array}$ & N/A & Total \\
$(18-20$ & 29.44 & 30.56 & 12.78 & 20 & 7.22 & 180 \\
\hline $21+$ & 15 & 21.67 & 11.67 & 51.67 & 00 & 60 \\
\hline Total & 25.83 & 28.33 & 12.5 & 27.92 & 5.42 & 240 \\
\hline
\end{tabular}

Table 10: Age by length of boyfriend/girlfriend relationships

As we can see, age is an important determinant. The older cohort (21 years + ) are, not surprisingly, likely to have been in longer 'boyfriend/girlfriend' relationships. Amongst 18-20 year olds, only $32.78 \%$ have been in a relationship of more than 12 months duration, whilst $63.34 \%$ of $21+$ year olds have been in such a relationship. 
For $36.6 \%$ of $18-20$ year olds, their experience of relationships is limited to 3 months, or none at all. Only $15 \%$ of $21+$ years olds fall into this category.

Thus, to summarise, the period $18-20$ is characterised by short term dating, leading to much longer lasting relationships in the $21+$ age category.

What gender differences exist in the length of relationships? Let us look at the 18-20 year old respondents $(n=180)$ in more detail (missing $=5$, a response rate of $97.29 \%)$.

\begin{tabular}{|c|c|c|c|c|c|c|}
\hline & $<3$ months & $3-11$ months & $\begin{array}{c}12-17 \\
\text { months }\end{array}$ & $>18$ months & N/A & Total \\
\hline Male & 43.6 & 32.7 & 9.1 & 7.3 & 7.3 & 100 \\
(No.) & $(24)$ & $(18)$ & $(5)$ & $(4)$ & $(4)$ & $(55)$ \\
\hline Female & & & & & & \\
$\%$ & 23.2 & 29.6 & 14.4 & 25.6 & 7.2 & 100 \\
$($ No.) & $(29)$ & $(37)$ & $(18)$ & $(32)$ & $(9)$ & $(125)$ \\
\hline Total & & & & & & \\
$\%$ & 29.4 & 31.11 & 12.77 & 20 & 7.22 & 100 \\
$($ No.) & $(53)$ & $(56)$ & $(23)$ & $(36)$ & $(13)$ & $(180)$ \\
\hline
\end{tabular}

Table11: Gender by length of boyfriend/girlfriend relationships

A number of interesting gender differences and similarities are apparent. The modal length of relationship for males aged 18 to 20 years is less than three months. Only $16.4 \%$ of males in this age group have been in a relationship for twelve months or more. A small group of $7.3 \%$ of males in the 18-20 years age group report having had no boyfriend/girlfriend relationship. For females, the modal length of relationship is 3-11 months. Two and a half times many females as males in this age group (40\% v 16.4\%) have been involved in relationships which have lasted for more than 12 months. Interestingly, the same proportion of females and males $(7.3 \%$ and $7.2 \%$ respectively) reported having had no relationships with boyfriends or girlfriends. Thus, we can conclude that females are more likely to be involved in longer lasting 
relationships at an earlier age than are boys. This, of course, confirms the common observation that young women typically date males older than themselves.

The 'length of relationships' has a bearing on whether one has been in a sexually active relationship (not necessarily involving full intercourse) or not. If we compare whether respondents report having been in a sexually active relationship with the length of the longest relationship they have been in, interesting patterns emerge:

\begin{tabular}{|l|l|l|l|l|l|l|}
\hline & $\begin{array}{l}<3 \text { months } \\
\%(\mathrm{~N})\end{array}$ & $\begin{array}{l}3-11 \text { months } \\
\%(\mathrm{~N})\end{array}$ & $\begin{array}{l}12-17 \\
\text { months } \\
\%(\mathrm{~N})\end{array}$ & $\begin{array}{l}\text { \% } \\
\text { (N) }\end{array}$ & $\%(\mathrm{~N})$ & $\%(\mathrm{~N})$ \\
\hline Yes & $20.56(37)$ & $27.22(49)$ & $14.44(26)$ & $36.67(66)$ & $1.11(2)$ & $75(180)$ \\
\hline No & $41.67(25)$ & $31.67(19)$ & $6.67(4)$ & $1.67(1)$ & $18.33(11)$ & $25(60)$ \\
\hline Total & $25.83(62)$ & $28.33(68)$ & $12.5(30)$ & $27.92(67)$ & $5.42(13)$ & $100(240)$ \\
\hline
\end{tabular}

Table 12: Duration of boyfriend/girlfriend relationships by 'ever in a sexually active relationship'

Let us consider the 60 individuals who have never been in a sexually active relationship (not necessarily involving intercourse)': 73\% of them have been in 'boyfriend/girlfriend' relationships of up to one year, suggesting 'early' sexual behaviour is not a feature of these relationships. On the other hand, $48 \%$ of those who have been 'in a sexually active relationship' have only been in a 'longest relationship' of less than one year. This suggests a wide continuum of sexual behaviour in short (less than one year) relationships, large numbers of which are sexually active, and large numbers of which are not.

It is also interesting to look at the gender differences in the dating behaviour of $21+$ year olds. All have had experiences of relationships of over 3 months at this stage. However, strong gender differences emerge: 


\begin{tabular}{|l|l|l|l|l|l|l|}
\hline & $<3$ months & $3-11$ months & $\begin{array}{l}12-17 \\
\text { months }\end{array}$ & $>18$ months & N/A & Total (N) \\
\hline Male & 28.57 & 28.57 & 28.57 & 14.29 & 0 & 14 \\
\hline Female & 10.87 & 19.57 & 6.52 & 63.04 & 0 & 46 \\
\hline Total & 15 & 21.67 & 11.67 & 51.67 & 0 & 60 \\
\hline
\end{tabular}

Table 13: Gender by length of relationships amongst 21+ year olds

Whilst the sample size for males (14) is very small, it is still interesting to note that nearly three times as many males as females (28.57\% v's $10.87 \%$ ) have still not have a boyfriend/girlfriend relationship which has lasted more than 3 months. On the other end of the scale, $63 \%$ of females aged $21+$ years have been in a relationship that has lasted 18 months or more, compared to only $14.29 \%$ of males. Again, this pattern of females engaging in longer relationships earlier than their male peers confirms the common observation that females typically date males older than themselves.

\section{Sexual orientation}

As we can see in Table 14 below, the majority of respondents described their sexual orientation as 'heterosexual.' Perhaps surprisingly, only one respondent reported a 'homosexual' orientation. Three describe themselves as 'bisexual' and two others responded that they are 'unsure' as to their sexual orientation. These figures seem lower than one might expect and may be explained by the requirement for respondents to categorise themselves, rather than detail a range of behaviours/experiences. Male prostitutes, for example, regularly engage in same-gender sex acts, commonly thought of as 'homosexual', whilst retaining their self-identity as 'heterosexual.' Likewise, the literature on adolescent sexual behaviour reports significant levels of 'samegender' sexual interaction, frequently interpreted as exploration or experimentation, as opposed to 'homosexuality.' A more operationalised question would most likely have yielded a greater diversity of same-gender experiences. 


\begin{tabular}{|cc|c|c|c|c|c|}
\hline & & Heterosexual & Homosexual & Bisexual & Unsure & Total \\
\hline Male & $\%$ & 98.6 & 0 & 1.4 & 0 & 100 \\
& $($ No. $)$ & $(68)$ & $(0)$ & $(1)$ & $(0)$ & $(69)$ \\
\hline Female & $\%$ & 97 & 0.6 & 1.2 & 1.2 & 100 \\
& (No.) & $(162)$ & $(1)$ & $(2)$ & $(2)$ & $(167)$ \\
\hline Total & $\%$ & 97.45 & 0.4 & 1.3 & 0.86 & 100 \\
& (No.) & $(230)$ & $(1)$ & $(3)$ & $(2)$ & $(236)$ \\
\hline
\end{tabular}

Table 14: Sexual orientation (response rate, $95.54 \%$, missing = 11)

Sample sizes are too small to make meaningful cross-tabulations by gender, age or place of origin.

\section{DISCUSSION}

The data allows us to make some observations about the sexual experiences of a sample of college students, which may or may not be comparable with other 18-21 year olds, let alone the general population:

\section{Sexual experiences below age 16}

- the majority of 16 year olds (84\%) have kissed an 'age mate' (that is, a partner younger than 21); about one third (30\%) have 'been masturbated by, or masturbated' an age-mate, and just over $12 \%$ have had intercourse.

- For the $10.2 \%$ of females in the sample who report having had intercourse below age 16, their male partners (regardless of age) have committed the offence of unlawful carnal intercourse (in fact, the true figure will be higher as respondents were not asked about their experiences of sexual intercourse whilst 16 years of age (this would also constitute an offence as the age of consent is 17).

- Males are one and half to two times more likely than females to report sexual experiences below age 16. However, we must recall that this paper has examined 'self-reports' of sexual behaviour and the over-reporting by males of 
sexual behaviour, and the under-reporting by females, has frequently been noted in the literature on this topic.

- Those with urban origins are significantly more likely to report having had sexual experiences before age 16 than those with rural origins

\section{Lifetime sexual experiences}

- $61 \%$ of males and $58 \%$ of females in the sample as a whole report having had sexual intercourse. For $18-20$ year olds, only $50.5 \%$ report having had sexual intercourse (57\% of males and $47.7 \%$ of females).

- Urban-rural differences persist beyond age 16. Respondents from Dublin city or county are more likely to report having had sexual intercourse than rural respondents (64\% and 39\% respectively). They are also more likely to have been involved in a sexually active relationship (76\% and 57\% respectively).

- Age is an important determinant of sexual intercourse. Thus, 50.5\% of $18-20$ year olds report having had sexual intercourse $(n=184)$, compared to $82 \%$ of 21-25 year olds $(n=44)$

- Age is also a determinant of respondents' experiences of boyfriend/girlfriend relationships. Amongst $18-20$ year olds, only $32.78 \%$ have been in a relationship of more than 12 months duration, whilst $63.34 \%$ of $21+$ year olds have been in such a relationship.

- Gender is a determinant of respondents' experiences of boyfriend/girlfriend relationships. Amongst 18-20 year olds, females are two and a half times more likely than males to have been in a relationship that has lasted more than 12 months. That is, females are more likely to be involved in longer lasting relationships at an earlier age than are males. This, of course, confirms the common observation that young women typically date males older than themselves.

- A significant proportion of 'boyfriend/girlfriend' relationships reported by the sample are not characterised by sexual activity. Conversely, other short term relationships (less than one year) are characterised by sexual activity. This suggests a wide continuum of sexual behaviour in short (less than one year) 
relationships, large numbers of which are sexually active, and large numbers of which are not.

\section{CONCLUSION}

Sexual behaviour amongst young people is subjected to wildly differing claims in the popular media and by various commentators. The perception exists that such behaviour is frequently promiscuous and irresponsible. This data suggests considerable variation between male/females and rural/urban populations. Sexual experiences amongst this sample of college students are not as widespread as might be imagined. It is hoped that this paper can provide a small degree of illumination to a topic where claims and counterclaims are not always empirically researched.

\section{REFERENCES}

Alliance (1997). What on earth are they doing? Cork: Alliance.

Department of Public Health, Midland Health Board. (1996). A Report on Sexual Practices of 16-18 Year Olds in the Midland Health Board. Midland Health Board: Department of Public Health.

Devlin, M. (this volume). Media representations of young people's sexuality.

DITSU (2000). DITSU Student Attitude Survey. Dublin: Dublin Institute of Technology Students' Union.

Fitzpatrick, C. C., Fitzpatrick, P. E. \& Turner, M. J. (1997). Profile of patients attending a Dublin adolescent antenatal booking clinic. Irish Medical Journal, 90, 3, 96-97.

Inglis, T. (1998). Lessons in Irish sexuality. Dublin: University College Dublin Press. 
Lalor, K. (1999). The incidence of unwanted childhood sexual experiences amongst a sample of third level students. Irish Journal of Psychology, 20(1), 15-28.

MacHale, E. \& Newell, J. (1997). Sexual behaviour and sex education in Irish school-going teenagers. International Journal of STD's and AIDS, 8, 3, 196200.

Rajani, R. \& Kudrati, M. (1996). The varieties of sexual experience of the street children of Mwanza, Tanzania. In S. Zeidenstein \& K. Moore (Eds.). Learning about sexuality: a practical beginning. New York: The Population Council.

Ryan, F. (1997). 'Queering' the criminal law: some thoughts on the aftermath of homosexual decriminalization. Irish Criminal Law Journal, 38. 